TẠP CHÍ KHOA HỌC ĐẠI HỌC TÂN TRÀO

ISSN: $2354-1431$

http://tckh.daihoctantrao.edu.vn/

\title{
Nhà mồ - tinh hoa của nghệ thuật kiến trúc dân gian Tây Nguyên
}

Ngô Văn Doanh*

Email:doanhngovan@gmail.com

\section{Thông tin bài viết}

Ngày nhận bài:

17/6/2018

Ngày duyệt đăng:

10/9/2018

\section{Tù khoá:}

Tây Nguyên, nghệ thuật kiến trúc dân gian Tây Nguyên, văn hóa dân gian Tây Nguyên.

\section{Tóm tắt}

Nhà mồ (nghĩa là nhà cho người chết) nhìn chung là có cùng kết cấu và hình dáng kiến trúc với nhà ở. Thế nhưng, thật khó tìm thấy trên Tây Nguyên một dạng kiến trúc nào có thể so sánh được với nhà mồ ở khía cạnh nghệ thuật điêu khắc và kiến trúc. Có lẽ, trên Tây Nguyên, nhà mồ là dạng kiến trúc duy nhất kết hợp vào mình nhiều lĩnh vực nghệ thuật khác nhau: kiến trúc, điêu khắc, vẽ, đan, nghệ thuật trang trí... Tùy thuộc vào đặc điểm và hình dáng của nhà mồ, mà những nét đặc trưng của kiến trúc, điêu khắc hay các trang trí được thể hiện ra hoặc nhiều hoặc ít.
Như bất kỳ mọi tác phẩm nghệ thuật kiến trúc khác, ở nhà mồ Tây Nguyên, việc giải quyết những nhiệm vụ thực dụng bao giờ cũng gắn bó mật thiết với sáng tạo nghệ thuật, nghĩa là với việc tạo ra những hình tượng kiến trúc thể hiện một nội dung tư tưởng nghệ thuật nhất định. Cho nên, vẻ đẹp hay giá trị của mỗi công trình kiến trúc đều được tạo bởi 2 yếu tố: nghệ thuật xây dựng và nội dung tư tưởng của hình tượng kiến trúc. Hai yếu tố này quan hệ hữu cơ với nhau: hình tượng là cái đích mà kiến trúc phải vươn tới, còn nghệ thuật xây dựng lại là cơ sở vật chất và kỹ thuật để kiến trúc thể hiện hình tượng của mình.

Nghệ thuật xây dựng là sự thể hiện những quy luật cấu trúc vốn có của kết cấu nhà cũng như kết cấu của những tác phẩm điêu khắc và trang trí. Nghệ thuật xây dựng được biểu lộ ở mối quan hệ qua lại và sự bố trí tương quan giữa những bộ phận chịu lực và không chịu lực, ở kết cấu nhịp điệu của các hình thức, ở kết cấu màu sắc của các tác phẩm nghệ thuật... Với đặc thù là kiến trúc nhà mồ, theo chúng tôi nghệ thuật xây dựng nhà mồ Tây Nguyên là nghệ thuật tạo lập không gian, là kỹ thuật sử dụng chất liệu, là nghệ thuật phối hợp tỷ lệ nhịp điệu và màu sắc giữa các thành phần kiến trúc với nhau để tạo ra một tác phẩm nghệ thuật thống nhất, hoàn hảo và độc đáo. Dưới đây là những phân tích của chúng tôi về những nét đẹp rất đặc trưng của nhà mồ Tây Nguyên.
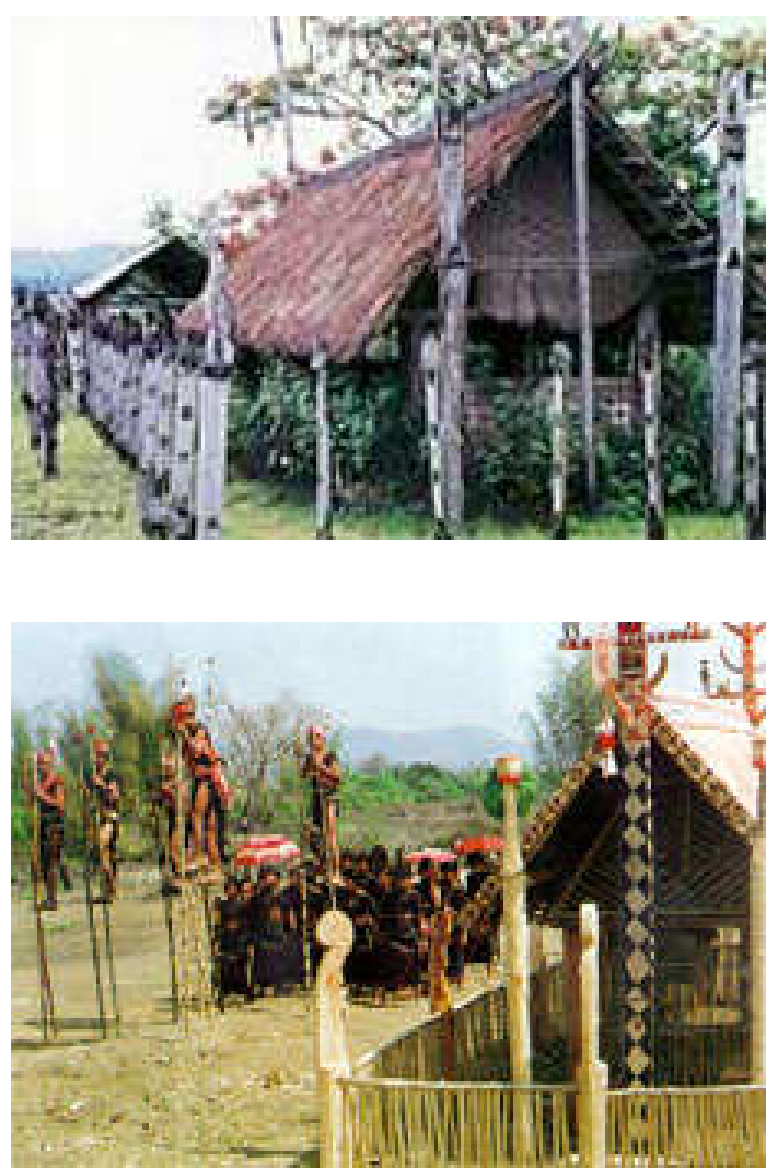


\section{Một môi trường không gian hoành tráng và nhân văn}
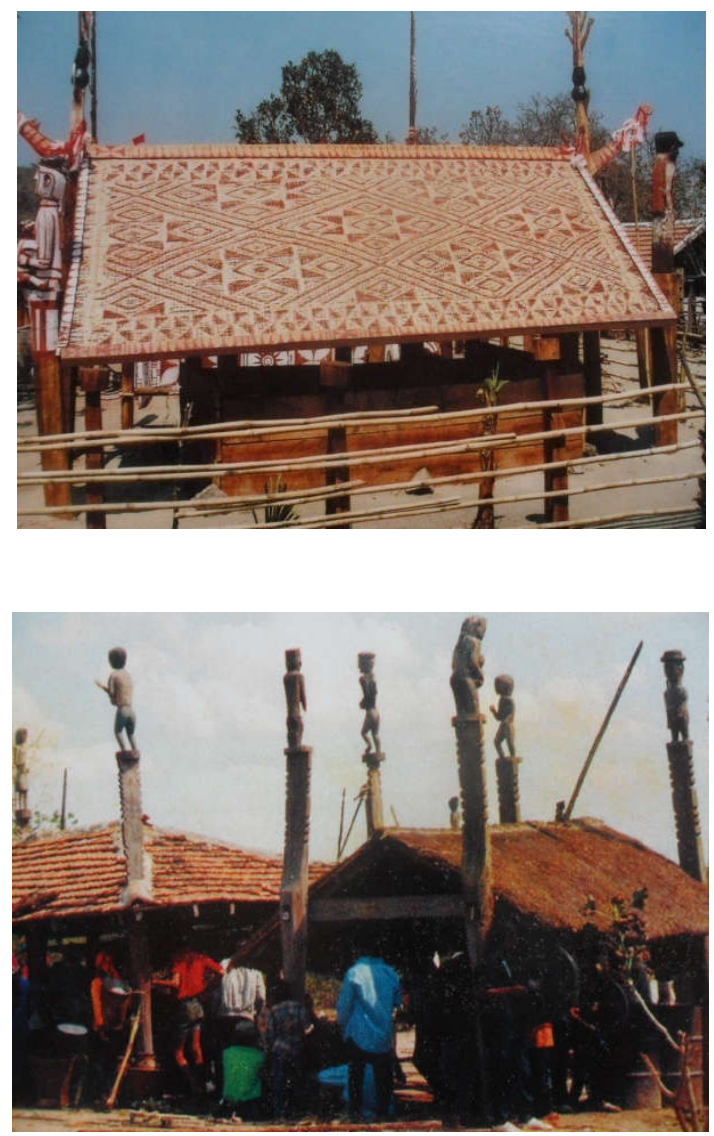

Kiến trúc bao giờ cũng là nghệ thuật thiết kế và xây dựng nên một môi trường không gian cho cuộc sống và cho hoạt động của con người. Nhà mồ Tây Nguyên, xét về mặt chức năng, là một môi trường không gian dành cho lễ hội bỏ mả - một lễ hội lớn nhất của nhiều dân tộc Tây Nguyên, chứ không phải là một kiến trúc để sử dụng lâu dài. Đoạn trích sau đây từ trường ca Xinh Chơ Niếp của người Êđê đã phần nào nói lên điều đó: "Về phần Chiêm Tơ Mun thì sau mấy mùa trăng lặn, trăng lên, sức khỏe của mẹ chàng đã hồi phục, làn da trở lại như xưa. Một buổi tối đầy sao, nhiều gió, chàng gọi Chiêm Mơ Nga tới nhà bàn việc làm lễ bỏ mả cho Đăm Di và Xing Chơ Niếp. Sau đấy họ đem rượu ra uống suốt mấy ngày liên tiếp bên đồi Lơ Mui. Mả Xinh Chơ Niếp và Đăm Di làm chung một chỗ, xây chung một hướng. Cây nêu cao tận trời, khắc trạm tận gốc. Bốn phía mồ đều đẽo tượng gỗ lớn. Tượng ngồi, tượng đứng, trông rất linh thiêng. Trai gái ở buôn gần dắt bò, buôn xa đem rượu tới ăn lễ. Chiêng trống không ngừng, nhảy múa không ngớt. Âm vang chấn động cả vách núi, lưng trời’"(1).
Hàng năm, khi mùa mưa vừa dứt, khi cửa kho lúa đã đóng, người Tây Nguyên bắt đầu chuẩn bị mọi thứ để làm lễ bỏ mả cho người chết. Họ phải chuẩn bị gạo nước, thịt rượu... Nhưng công việc chính bao giờ cũng là chuẩn bị và dựng nhà mồ. Suốt mấy tuần liền, thậm chí cả hàng tháng trời, dân làng rủ nhau vào rừng đẵn gỗ, chặt tre, cắt mây, song, cắt cỏ gianh đem về khu nghĩa địa của làng. Còn ở nghĩa địa thì tấp nập suốt ngày đêm, người chặt cột, người đan mái, người đẽo tượng, người tô vẽ, người dọn dẹp, người phục vụ... Mọi người vừa làm và truyền nghề cho nhau, vừa bàn chuyện làng, chuyện xóm... Đến hôm vào lễ bỏ mả thì ngôi nhà mồ đã rực rỡ mọc lên giữa một khu nghĩa địa phong quang, sạch sẽ.

Vì nhà mồ chỉ có ý nghĩa sử dụng trong những ngày làm lễ bỏ mả (từ $3-7$ ngày) cho nên nó chỉ phát huy hết hiệu quả nghệ thuật của mình trong những ngày đó. Do vậy, muốn thấy được vẻ đẹp, giá trị nghệ thuật thực sự của nhà mồ Tây Nguyên, ta phải nhìn nó, quan sát nó đúng vào những ngày hội lễ bỏ mả. Sau lễ bỏ mả, ngôi nhà mồ cũng bị bỏ luôn. Và sau đó, mưa gió sẽ làm phai dần các sắc màu trang trí, làm đổ nát những bộ phận kiến trúc mềm yếu, và cỏ cây sẽ mọc lên lấn át dần cả môi trường không gian kiến trúc nhà mồ. Ngoài ra, sau lễ bỏ mả, sẽ không còn âm thanh của cồng chiêng, tiếng nhảy múa rộn ràng của những người dự lễ, những ánh lửa bập bùng trong đêm... Theo quan niệm của người Tây Nguyên, nhà mồ là một môi trường không gian sống chứ không phải là một đài tưởng niệm. Ngôi nhà mồ chỉ tồn tại, chỉ sống trong mấy ngày hội lễ bỏ mả ngắn ngủi thôi.

Vào những ngày lễ bỏ mả, nhà mồ với những sắc màu rực rỡ, chủ yếu là các màu thuộc gam màu nóng như đỏ, vàng nổi bật lên trên một khu đất cũng màu đỏ (màu đất đỏ của Tây Nguyên). Tất cả các màu đều tươi nguyên; khu nghĩa địa vừa được dọn dẹp phát quang làm lộ ra màu đất đỏ tươi, mái gianh óng ả màu vàng ươm của cỏ khô, những chiếc cột trang trí, những pho tượng gỗ, những hình chạm khắc còn tươi rói và thơm tho mùi gố; những hình đan còn mới nguyên màu vàng của cật tre... Từ bản thân kiến trúc nhà mồ đến không gian dành cho hội lễ đều bừng lên bởi những gam màu nóng. Cho nên, tuy thật bé nhỏ so với thiên nhiên bao quanh, nhưng nhà mồ như nổi bật lên, bay lên trên cả một biển màu xanh bao la của núi rừng trùng điệp. Đó là hiệu quả nghệ thuật của sắc màu tương phản. Chưa hết, sự đối lập giữa nhà mồ và 
không gian bao quanh còn biểu hiện cả ở nhịp điệu và âm thanh. Tiếng cồng chiêng trầm hùng suốt đêm ngày của lễ bỏ mả, như mô tả của bài trường ca đã dẫn ở trên, "chấn động cả vách núi, lưng trời”. Đêm xuống, bức tranh của nhà mồ càng uy nghi, hoành tráng hơn: hàng trăm đống lửa rực sáng, bừng lên giữa âm $u$ tĩnh mịch của núi rừng và tiếng trống chiêng càng rộn rã thôi thúc và mạnh mẽ hơn.

Nhà mồ Tây Nguyên chính là một hình tượng nghệ thuật mang tính nhân văn của người Tây Nguyên trong quan niệm về sự sống và cái chết cũng như về mối quan hệ giữa con người và thiên nhiên.

\section{Tầm vóc của con người}

Có thể nói, không một dạng kiến trúc nào ở Tây Nguyên, thậm chí cả nhà rông, lại hút được nhiều lĩnh vực nghệ thuật khác nhau vào mình như nhà mồ. Nhà mồ là kiến trúc, nhà mồ là nghệ thuật trang trí, nhà mồ là nghệ thuật đan lát... Thế nhưng, nhà mồ lại thuộc loại những kiến trúc nhỏ chứ không lớn. Họa hoằn lắm mới có một ngôi nhà mồ cao to bằng nhà ở (trong những trường hợp nhà mồ được làm cho nhiều người chết), còn hầu hết thì chỉ nhỉnh hơn kho lúa hay cái chòi nương một tý.

Mặc dầu bản thân ngôi nhà không lớn, nhưng các yếu tố phụ như các tượng gỗ, các cột trang trí cao thấp khác nhau; nhưng băng chạm khắc, tô vẽ trên nóc, trên mái, lại phối hợp với nhau, tạo ra dáng vẻ hùng vĩ và hoành tráng cho tổng thể kiến trúc nhà mồ. Nếu đem so với kích thước của ngôi nhà phía trên nấm mộ ở chính giữa tổng thể nhà mồ thì những bộ phận phụ cũng có kích thước không lấy gì làm to lớn lắm: các tượng mồ to nhất cũng chỉ bằng kích thước của con người, các cột trang trí cao nhất cũng được tạo bởi từng phần nhỏ chắp nối lại với nhau, mà mỗi phần nhỏ có chiều cao tối đa là chiều cao của con người.

Ở nhà mồ Tây Nguyên, tất cả các bộ phận hợp thành đều có kích thước lấy từ chuẩn mực của con người: tượng không cao quá một sải và không ngắn dưới một gang, các băng chạm khắc thường có chiều rộng một gang, những chiếc cột trang trí được tạo từ các bộ phận ngắn chắp vào; những ngôi nhà mồ nhỏ thường dài 2 sải, rộng 1 sải, cao sải rưỡi; khoảng cách từ lối hàng rào cột bao quanh đến ngôi nhà bên trong thường từ nửa sải đến một sải tay... Hầu như không một bộ phận trang trí nào ở nhà mồ có chiều cao quá 1 sải, tức quá tầm vóc của con người. Thế nhưng, để tăng chiều cao cho những hình trang trí, người Tây Nguyên thường sử dụng những biện pháp kỹ thuật lắp ghép, chắp nối hoặc trang trí nhiều hình liên tục lên một thân gỗ dài... Ví dụ, một thân gỗ dài có thể vừa làm cột rào (phần phía dưới) vừa làm tượng mồ hay các hình trang trí (phần phía trên). Những cột trang trí cao thì được làm hoặc như đối với cột tượng (trong trường hợp có cây gỗ dài) hoặc chắp các bộ phận trang trí vào với nhau (trong trường hợp cây gỗ ngắn hơn sự cần thiết). Các băng trang trí trên nóc nhà mồ cũng được tạo bởi từng cảnh, từng hình ngắn chắp lại. Bằng những biện pháp kỹ thuật đơn giản nhưng thông minh như vậy, người Tây Nguyên có thể dựng lên những cột trang trí nhà mồ "cao đến tận trời”. Thế nhưng, không một hình tượng hay một họa tiết trang trí riêng biệt nào lớn hơn tầm vóc của con người cả.

Trong kiến trúc cũng như trong nghệ thuật tạo hình, có nhiều cách tạo hình hoành tráng cho tác phẩm: hoặc bằng kích thước lớn, hoặc bằng màu sắc đường nét và hình khối; hoặc bằng bố cục và tỷ lệ, hoặc bằng cách kết hợp cả ba yếu tố trên. Cho nên, có những tác phẩm thật lớn mà vẫn không hoành tráng, trong khi đó, có những tác phẩm thật nhỏ mà lại rất hoành tráng. Nhà mồ Tây Nguyên thuộc dạng thứ hai. Để tạo tính hoành tráng cho nhà mồ, người Tây Nguyên đã áp dụng nhiều biện pháp thông minh và có hiệu quả về mặt nghệ thuật xây dựng.

Xét về mặt cấu trúc, nhà mồ Tây Nguyên bao giờ cũng gồm ba bộ phận chính: lối hàng rào gồm các cột tượng và cột trang trí bao quanh bên ngoài, ngôi nhà ở trong và phần trang trí phía trên nóc nhà (hoặc là hàng chạm khắc hoặc là cột trang trí). Bố cục của 3 bộ phận đó là bố cục hướng tâm và tỷ lệ chiều cao của các bộ phận là nhịp điệu nâng cao dần. Ngôi nhà ở trong vừa làm nền cho các tượng gỗ bên ngoài vừa làm bệ cho các hình trang trí phía trên. Các tượng phía ngoài, nhờ có phần cột phía dưới, mà cao hơn tầm vóc người thực, nhưng lại không được át chiều cao của ngôi nhà. Lối rào bao quanh che kín toàn bộ phần nền và các chân cột lại có tác dụng khiến cho người xem cảm thấy ngôi nhà bên trong như cao lên, như đang lơ lửng trong không gian. Đến lượt mình, ngôi nhà lại đội các hình trang trí ở nóc cao hơn các cột tượng bên ngoài. Cho nên, tuy các cột trang trí bên trong khá cao (có cột cao tới gần $10 \mathrm{~m}$ ), nhưng các hình trang trí lại không bị chiều cao nuốt chửng vì có bộ mái làm nền. 
Hơn thế nữa, hình dáng và nhịp điệu kết cấu của toàn bộ các bộ phận và các chi tiết của nhà mồ đều có xu thế vươn cao và nâng đỡ nhau. Lối hàng rào bao quanh cao chừng nửa sải có bình đồ chữ nhật, hoặc vuông có tác dụng che khuất phần chân của ngôi nhà bên trong để nhân chiều cao và dáng bay cho ngôi nhà, vừa có vai trò giới hạn không gian cho tổng thể kiến trúc. Nếu không có lối hàng rào làm giới hạn thì các cột trang trí và cả ngôi nhà sẽ dễ bị hòa tan vào khoảng đất màu đỏ khá rộng của khu nghĩa địa, và như vậy sẽ mất hẳn tính hoành tráng cùng nhịp điệu bay lên của nhà mồ. Ngoài ra, cái hình vuông hay chữ nhật có giới hạn và góc cạnh của lối hàng rào lại như tạo ra sức nặng, sức bám cho kiến trúc, không để cho các cột trang trí nhỏ bé, đang lơ lửng trên không trung, không thể bứt ra khỏi cái không gian của mình để hòa nhập vào một môi trường khác, khung cảnh khác. Kết quả là, như từng nhạc cụ riêng biệt, dưới bàn tay điều khiển của người nhạc trưởng là các nghệ nhân dân gian, tất cả các bộ phận cấu thành nhà mồ Tây Nguyên cùng phối hợp, dạo lên một bản nhạc giao hưởng hùng tráng. Trong "bản giao hưởng nhà mồ" đó, tầm vóc của con người được đề cao, được nâng lên vượt khỏi bản thân con người.

Ở nhà mồ Tây Nguyên, nhờ nghệ thuật kiến trúc, mà tất cả những hình ảnh, những hình tượng nhỏ bé như tầm vóc của con người đã gây được một hiệu quả hoành tráng đặc biệt: vừa gần gũi với con người, vừa vươn lên ngang tầm với sự hùng vĩ của thiên nhiên.

\section{Thiên nhiên và con người}

Để làm nhà mồ, người Tây Nguyên không phải đi đâu xa để lấy vật liệu, mà lấy ngay những sản phẩm của núi rừng bao quanh xóm làng như: gỗ, nứa, song, mây, cỏ gianh... Thế nhưng, vật liệu bao giờ cũng chỉ là cái cơ sở vật chất ban đầu. Từ vật liệu đến tác phẩm kiến trúc là cả một quá trình kỹ thuật và nghệ thuật.

Thoạt nhìn vào cấu trúc của bất kỳ một ngôi nhà mồ Tây Nguyên nào, ta dễ có cảm tưởng về một nền kỹ thuật xây dựng thô sơ: chỉ có gá buộc chứ không có hệ thống liên kết bằng mộng, vật liệu xây dựng chỉ là gỗ, tre, nứa, lá chứ không có gạch, đá, công cụ xây dựng chỉ có dao và rìu chứ không có cưa, bào, đục... Thế nhưng, chính với những kỹ thuật đơn sơ như vậy, người Tây Nguyên đã, đang và sẽ còn tạo ra những công trình kiến trúc nhà mồ có một vẻ đẹp riêng - vẻ đẹp của chất liệu tự nhiên.
Do chỉ có chức năng và mục đích mang tính tạm thời - phục vụ cho mấy ngày lễ hội bỏ mả, do vật liệu xây dựng là những vật liệu nhẹ, dễ bị hư hỏng, nên thật khó có thể tìm thấy ở Tây Nguyên những nhà mồ cổ xưa. Thế nhưng, như các trường ca sử thi đã phần nào cho chúng ta biết, ngay từ xa xưa, người Tây Nguyên đã biết cách lựa chọn những vật liệu thích hợp của rừng để làm nhà mồ. Trong trường ca Chi Lơ Kok của người Êđê có đoạn: "Xing Chi Ngă kêu buôn dưới, làng trên vào rừng chặt cây kơ dăm cây mơ-pih, hạ những cây gòn to nhất để làm nhà mồ cho Chi Lơ

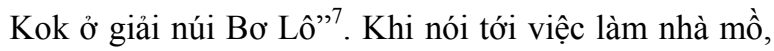
bản trường ca "Xing Nhã" viết: "Xing Nhã sai nô lệ vào rừng chặt cây kơ-nia, những cây gòn to nhất để dựng nhà mồ cho cha là Gia-rơ Kốt"(2).

Tùy theo phẩm chất của từng loại cây mà người Tây Nguyên sử dụng chúng vào những bộ phận thích hợp của nhà mồ: những cây gỗ cứng được dùng làm cột, kèo và để đẽo tạc các loại cột tượng, cột trang trí - nghĩa là những bộ phận chịu lực và có kích thước lớn, những cây gỗ mềm được dùng để làm các hình trang trí nhỏ, những tượng nhỏ, những hình cắt...; Song, mây vừa bền, vừa dẻo, vừa dai, được dùng làm dây buộc, cỏ gianh không thấm nước được dùng để lợp mái, nứa tre được dùng để đan các họa tiết trang trí và các tấm phên giúp giữ mái. Người Bana thường sử dụng các loại gỗ cứng như to'-nung (cẩm lai), to chứt (gỗ hương), to gier (gỗ gụ) để làm các cột, xà và đẽo tượng, và dùng các loại cây mềm như blang (cây gòn), do táp (cây vông) để làm các hình chạm khắc nhỏ. Để làm cột kèo và đẽo các tượng lớn, người Giarai dùng gỗ napan (gỗ hương), nạ pắc (gỗ cây đỏ vỏ); còn để làm các hình trang trí nhỏ, họ dùng các loại cây gỗ có thân mềm như $n a$ h'rái (cây dầu rái), $n a$ nác, na do rôl...

Do được sử dụng đúng vị trí, đúng chức năng nên các loại chất liệu của thiên nhiên đã phát huy một cách có hiệu quả về cả kỹ thuật và nghệ thuật của mình ở kiến trúc nhà mồ. Những chiếc cột nhà, cột tượng và chân các cột trang trí có độ cao lớn không chỉ bền cứng để chịu lực mà cái màu xám hơi tối của chất gỗ gây ra cho thị giác người xem một ấn tượng vững chãi và chắc chắn. Cỏ gianh, tấm đan bằng cật nứa, cật tre không chỉ giảm độ nặng cho mái mà màu vàng ươm của chất liệu cỏ khô, cật nứa già tạo cho phần trên của kiến trúc một cảm giác nhẹ nhàng, bay bổng. Thân của những cây gỗ mềm màu sáng tươi vừa là chất liệu lý 
tưởng để dùng dao khắc, cắt những hình trang trí nhỏ gắn vào nóc nhà và đỉnh các cột trang trí, vừa tạo ra một sắc màu thoáng mát, dễ chịu và có phần bồng bềnh, huyền ảo cho các phần cao nhất của nhà mồ. Những chiếc dây mây, song vừa bền dẻo để buộc vừa tạo ra ở các chỗ nối những khối nổi mang tính mỹ thuật cả về hình dáng lẫn màu sắc tự nhiên hài hòa.

Ở nhà mồ Tây Nguyên, các chất liệu của thiên nhiên đã được con người sử dụng một cách hợp lý, đúng chỗ và phù hợp với phẩm chất của từng loại cỏ cây. Nhờ vậy mà các dân tộc Tây Nguyên không chỉ làm ra được những hình tượng thích hợp, mà còn tạo ra cho chúng những màu sắc tự nhiên tương ứng cho kiến trúc nhà mồ. Cho nên, khi nhìn vào nhà mồ, người xem lập tức thấy ngay, nhận ra ngay cái âm hưởng bay bổng và hoành tráng không chỉ của các hình khối mà của cả các sắc màu, tất cả đều hiện lên hồn nhiên, trong sáng và nguyên chất.

\section{TÀI LIỆU THAM KHẢO}

1. Xing Cho Niếp (trường ca Ê - đê) (1986), Nxb Văn hóa, Hà Nội, tr.129;

2. Xing Nhã, Đăm Di (trường ca $\hat{\mathrm{E}}$ - đê) (1978), Nxb Văn hóa dân tộc, Hà Nội, tr.77.

\section{Charnel house - a great feature of Tay Nguyen architecture}

\section{Ngo Van Doanh}

\section{Article info}

\section{Recieved:}

17/6/2018

Accepted:

10/9/2018

Keywords:

Tay Nguyen,folk architecture of Tay Nguyen, folk culture of Tay Nguyen.

\begin{abstract}
The Charnel-house (means a house for the dead) commonly has the same architectural structure and shape to the dwelling house. However, it is difficult to find in Vietnam Central Highlands any other architecture that is comparable to that of the Charnel-house in the field of sculpture and architectural art. Perhaps, in Central Highland the Charnel -house is the only architecture that combines many different branches of art: architecture, sculpture, drawing, plating, decorative art... Depending on the character and the shape of the tombs-house, the artistic character of the architecture, sculpture or decorations make it more or less evident.
\end{abstract}

